\title{
Prevalence and risk factors related to poor outcome of patients with severe Plasmodium vivax infection: a systematic review, meta-analysis, and analysis of case reports
}

\author{
Manas Kotepui ${ }^{1 *}$, Kwuntida Uthaisar Kotepui ${ }^{1}$, Giovanni De Jesus Milanez ${ }^{2}$ and Frederick Ramirez Masangkay ${ }^{2}$
}

\begin{abstract}
Background: Plasmodium vivax rarely develops severe complications when compared to severe falciparum malaria. However, severe vivax malaria also needs urgent, intensive care and treatment as severe falciparum malaria. This systematic review aimed to explore pooled prevalence of severe vivax malaria and to identify factors related to poor outcome of patients who developed severe manifestation.

Methods: The systematic review conducted by two reviewers independently through searching of research publications related to severe P. vivax malaria in three databases including MEDLINE, Web of Science (ISI), and Scopus until October, 22 2019. The pooled prevalence of severe vivax malaria was achieved using STATA and RevMan 5 Software. Factors related to poor outcome of patients with severe vivax malaria were analyzed using SPSS 11.5 Software.

Results: Among 2615 research publications retrieved from three databases, 49 articles reporting on 42,325 severity cases were selected for calculating pooled prevalence. Seventy-six patients from case reports, case series, letter to editors, and research communications were collected to identify factors related to poor outcome of patients with severe vivax malaria. The results showed that severe anemia, jaundice, respiratory distress, impaired consciousness, and renal failure were the most common major manifestations of severe malaria guided by the World Health Organization (WHO) criterion. The meta-analysis indicated that severe malaria was less frequent in patient with $P$. vivax compared to those with $P$. falciparum $\left(P\right.$-value $\left.<0.00001, \mathrm{OR}=0.38,95 \% \mathrm{Cl}=0.25-0.56, \mathrm{I}^{2}=87 \%\right)$. In addition, thrombocytopenia, anemia, hepatitis, and severe thrombocytopenia were the most common minor complications. Analysis of cases indicated that convulsion, respiratory distress, renal failure, jaundice, anuria/oliguria, and complication during treatment impacted on longer hospital stays compared to other severe complications $(P$-value $<0.05)$. Respiratory distress was frequently found after first treatment with anti-malarial drugs ( $P$-value $=0.002$ ). Renal failure was frequently found before treatment with anti-malarial drugs $(P$-value $=0.016)$. Mean days of fever and higher pulse rates at presentation were predictors of poor outcome among patients with severe vivax malaria ( $P$-value $<0.05)$.

(Continued on next page)
\end{abstract}

\footnotetext{
* Correspondence: manas.ko@wu.ac.th

${ }^{1}$ Medical Technology, School of Allied Health Sciences, Walailak University,

Thasala, Nakhon Si Thammarat, Thailand

Full list of author information is available at the end of the article
}

(c) The Author(s). 2020 Open Access This article is licensed under a Creative Commons Attribution 4.0 International License, which permits use, sharing, adaptation, distribution and reproduction in any medium or format, as long as you give appropriate credit to the original author(s) and the source, provide a link to the Creative Commons licence, and indicate if changes were made. The images or other third party material in this article are included in the article's Creative Commons licence, unless indicated otherwise in a credit line to the material. If material is not included in the article's Creative Commons licence and your intended use is not permitted by statutory regulation or exceeds the permitted use, you will need to obtain permission directly from the copyright holder. To view a copy of this licence, visit http://creativecommons.org/licenses/by/4.0/ The Creative Commons Public Domain Dedication waiver (http://creativecommons.org/publicdomain/zero/1.0/) applies to the data made available in this article, unless otherwise stated in a credit line to the data. 
(Continued from previous page)

Conclusions: Severe anemia was the most common major manifestation of $P$. vivax malaria guided by the WHO criterion. Severe anemia was found less frequently in patients with P. vivax than those with P. falciparum. Renal failure, jaundice, anuria/oliguria, and complication during treatment along with, mean days of fever and higher pulse rates at presentation might be predictors of poor outcome of patients with severe vivax malaria.

Keywords: P. vivax, Discharge, Treatment outcome, Severe malaria, Poor outcome

\section{Background}

Plasmodium spp. infection among humans were estimated at 228 million cases of malaria occurring worldwide in 2018, especially in the African Region (213 million or 93\%), followed by the South-East Asia Region (3.4\%) and the Eastern Mediterranean Region (2.1\%) with an estimated 405,000 deaths [1]. P. vivax infection was manifested in the South-East Asia Region (53\%), with the majority being in India (47\%) [1]. Plasmodium vivax is one of five Plasmodium species infecting humans and is recognized as less severe than Plasmodium falciparum infection. However, severe vivax malaria is a medical emergency defined as one or more complications with the presence of $P$. vivax asexual parasitemia with no parasite density threshold [2]. The major complications of severe malaria as defined by the World Health Organization (WHO) 2014 included impaired consciousness, jaundice, pulmonary edema, acute renal failure, severe anemia, bleeding, acidosis, hyperparasitemia, respiratory distress, and hypoglycemia [2]. Any of these complications can develop rapidly and progress to death within hours or days. In recent years, a large number of case reports about severe malaria caused by $P$. vivax have been reported. Previous studies indicated that $P$. vivax infections can lead to severe malaria including renal failure [3-5], bleeding [6, 7], hyperparasitemia $[8,9]$, impaired consciousness [9-12], jaundice $[6$, $13,14]$, prostration [15], pulmonary edema [16-18], respiratory distress [19-22], severe anemia [4, 14], and shock [23, 24].

This systematic review, meta-analysis, and analysis of cases aimed to highlight the prevalence of severe malaria severe complications caused by $P$. vivax malaria. The secondary objective was to identify factors related to poor outcome of patients who developed severe vivax malaria in literatures.

\section{Methods}

\section{Search of articles from 3 published databases}

This systematic review and meta-analysis was reported according to the PRISMA statement guidelines [25]. The searches were performed in the three published databases including MEDLINE, Web of Science (ISI), and Scopus. The searches focused on studies related to the prevalence and individual patient reports (case reports and also case series, correspondences, letter to editors) of severe vivax malaria, which published up to October 22, 2019. The search strategy used to retrieve relevant articles was the following "Plasmodium vivax"[All Fields] AND "complications"[All Fields]. EndNote Version X7 (Tomson Reuters, New York, NY) was used to manage references retrieved in this study.

\section{Eligibility criteria}

All studies in the English language which reported prevalence, incidence, and individual case reports of severe vivax malaria infection were included. Exclusion criteria included any studies that reported animal studies, clinical drug trial/drug studies, experimental/investigation studies, placental/maternal malaria, $P$. vivax with no related topic/no complication, studies not about malaria prevalence, malaria studies but not on $P$. vivax infection, co-infection with other agents/with underlying diseases, reviews, and co-infection of other species of Plasmodium spp., which were excluded after screening the titles and abstracts. Only articles reporting on severe $P$. vivax mono-infection were selected. Studies were additionally excluded following full-text review if they reported incomplete prevalence on severe vivax complications.

\section{Data extraction}

Two independent reviewers (Manas Kotepui and Kwuntida Uthaisar Kotepui) were responsible for searching and selecting articles associated with the inclusion criteria. First, Endnote X7 Software (Clarivate Analytics, Canada) was used to manage the references retrieved from three databases. Duplicate references among the three databases were excluded. The references were then being screened for their title and abstract. Screened articles were examined for full text evaluation. Any discrepancy between two reviewers were consulted with two independent reviewers (Giovanni De Jesus Milanez and Frederick Ramirez Masangkay) to determine whether articles can be included in the study. The articles that passed the inclusion and exclusion criteria were encoded into an Excel Spreadsheets (Microsoft, USA). Each article contained these data: author, year of publication, severity sign, age, gender, country of infection, fever, days of fever, signs and symptoms at presentation, pulse, 
respiratory rate, systolic blood pressure, diastolic blood pressure, spleen and liver abnormality, hemoglobin, leukocyte count, platelet count, stage of $P$. vivax found in blood film examination, Rapid diagnostic test (RDT) used in the study, time point of severity sign, complication after treatment, number of anti-malarial drugs given, discharged days, improving days, and days of parasite clearance.

\section{Criteria of severe malaria and treatment outcome}

Criteria of severe vivax malaria was defined by the WHO Guidelines including impaired consciousness, convulsion, prostration, pulmonary edema, acute renal failure, severe anemia, bleeding, jaundice, acidosis, hyperparasitemia, respiratory distress, and hypoglycemia with no parasite density threshold [2]. Those complications defined by the WHO Guidelines were categorized as major complications, whereas other complications reported in literatures which were not defined by the WHO Guidelines, were reported as minor complications in the present study. Treatment outcome of severe malaria on case reports was based on the number of days discharged from hospital and also days of improving from severe manifestation. The number of discharged days was divided as follows: less than one week as a good outcome, whereas more than one week as a poor outcome.

\section{Meta-analysis}

The pooled prevalence and 95\% CI of complications among severe vivax malaria was undertaken to perform a meta-analysis with STATA Software Version 16 (Stata Corp LP, Texas USA). The pooled prevalence was calculated following a previous research [26] by using the the following command in STATA:

\section{Metaprop case population, random}

The prevalence of severe complications between $P$. vivax and P. falciparum was assessed using Cochrane Q (Chisquare) with Odds ratio, Moran's $\mathrm{I}^{2}$ (Inconsistency), and subgroup analyses using RevMan 5 Software (Version 5, London, UK) [27]. A random-effects model was used to estimate the summary Mantel-Haenszel odds ratio of severe complications among patients infected with $P$. vivax and those with $P$. falciparum.

\section{Statistical analysis}

In order to identify factors related to poor outcome of severe vivax malaria, individual patient's data from all case reports, case series, letter to editors, and correspondences were input to SPSS 11.5 Statistical Software (SPSS Inc., Chicago, USA). Qualitative demographic data (e.g., gender, nationality, severity sign, country of infection, clinical and laboratory parameters time point of severe manifestation, treatment outcome, etc.) were analyzed using the frequency, percentage, and Chi-squared test with 95\%CI. Differences among quantitative variables such as age, temperature, systolic blood pressure, diastolic blood pressure, pulse rate, days of fever, hemoglobin, leukocyte count, and platelet count between two groups were analyzed by an independent sample $\mathrm{T}$ test or Mann Whitney $\mathrm{U}$ test upon the distribution of the data.

\section{Results}

\section{Search results}

All 3229 research articles were retrieved from three databases (866 from MEDLINE, 2281 from Scopus, and 82 from Web of Science). After deleting duplicate references, the titles and abstracts of 2615 articles were screened. Out of 849 articles that were selected for fulltext screening, 123 articles were included for further review. Out of these 123 articles, 49 articles reporting prevalence of severe vivax malaria for calculating pooled prevalence were further selected and included for pooled analysis. In addition, out of 203 individual patient reports (from case reports and also case series, correspondences, letter to editors), 76 individual cases reporting on the prevalence of severity signs were selected based on the criteria for severe vivax malaria and used to identify factors related to poor outcome of severe vivax malaria in our study (Fig. 1).

\section{Characteristics of included studies Articles for calculating pooled prevalence and $95 \% \mathrm{Cl}$} Characteristics of the 49 studies included in this study are listed in Table 1 and Fig. 2. Most of the studies reported severity signs of $P$. vivax malaria infection in 2013 (14, 28.6\%), following by 2012 (6, 12.2\%), 2014 (5, $10.2 \%)$, and 2016 (5, 10.2\%). Most of the study' participants were from India (25, 51\%), Pakistan (6, 12.2\%), and Indonesia $(5,10.2 \%)$.

\section{Articles for identifying factors related to poor outcome of severe vivax malaria}

Characteristics of the 76 studies with individual patient' reports were listed in Table 2. All studies reported severe vivax malaria during 1993-2019. Most of the reports were published in 2010 (17, 22.2\%), 2013 (11, $14.5 \%)$, and 2016 (6, 7.9\%). Most of the major severe complications among reports were renal impairment $(28,36.8 \%)$, respiratory distress $(22,28.9 \%)$, and impaired consciousness $(21,27.6 \%)$.

\section{Prevalence of severe vivax malaria}

Among 49 studies reporting on 42,325 severity cases, 21 reported impaired consciousness, 1 prostration, 8 convulsion, 4 acidosis, 22 respiratory distress, 8 severe 


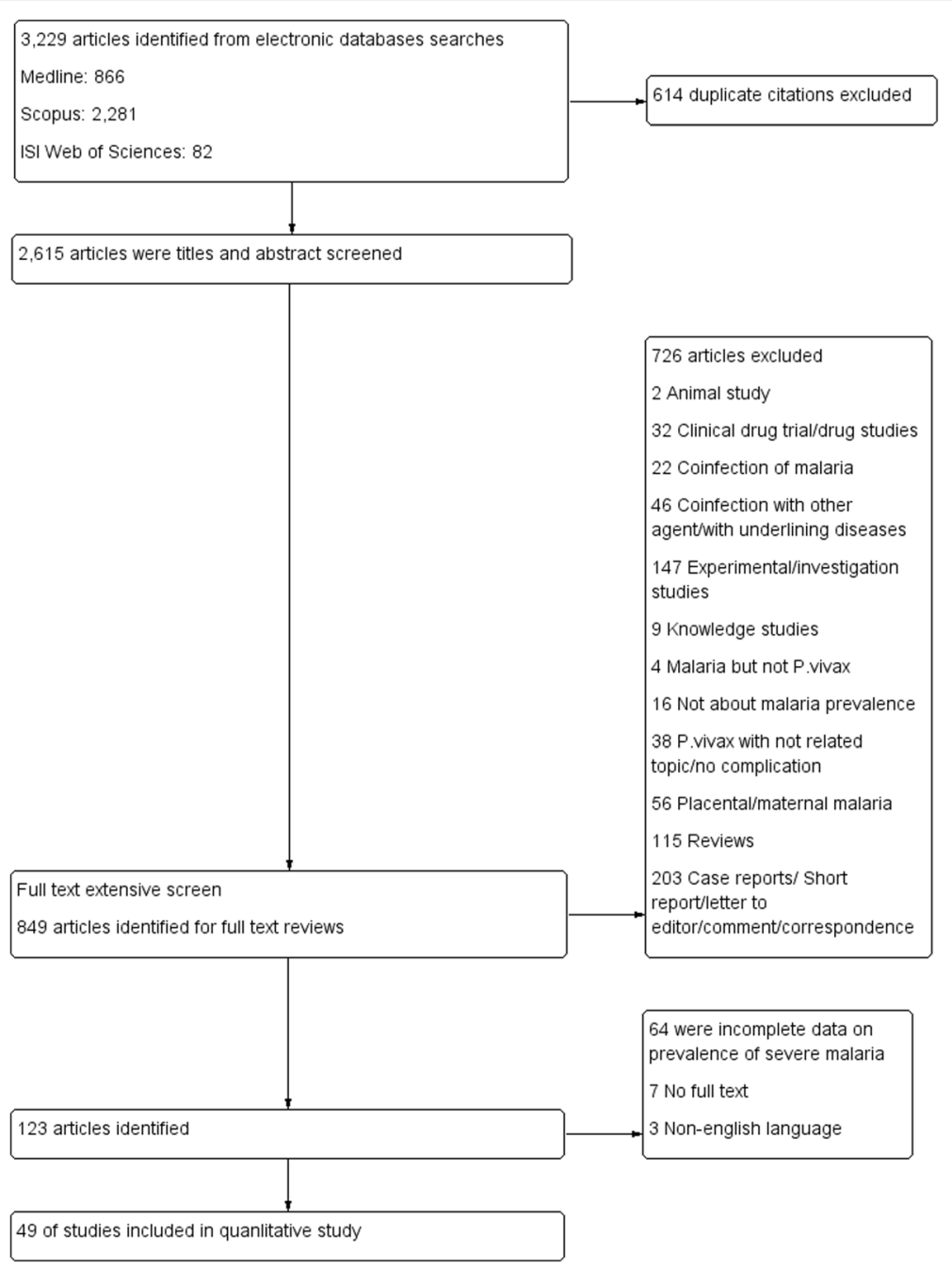

Fig. 1 PRISMA diagram. Flow chart for study selection

anemia, 28 renal failure, 19 jaundice, 3 pulmonary edema, 8 bleeding, 6 shock, and 2 studies reported hyperparasitemia. The prevalence of severe complications of each study is shown in Fig. 2. The pooled prevalence of each severe manifestation according to the WHO criteria is shown in Fig. 3. Moreover, the pooled prevalence of each minor complication including thrombocytopenia, severe thrombocytopenia, hyperpyrexia, severe vomiting, drossiness, hepatitis, sudden cardiac arrest, hemoglobinuria/hematuria, and moderate anemia is shown in Fig. 4.

Among these studies, the pooled prevalence of the five most commonly reported major complications were: severe anemia $0.02 \%$ (95\% CI: 0.02, 0.03), jaundice $0.01 \%$ (95\% CI: 0.01, 0.02), respiratory distress $0.01 \%$ (95\% CI: $0.01,0.01$ ), impaired consciousness $0.01 \%$ (95\% CI: 0.01, 0.01 ), and acute renal failure $0.01 \%$ (95\% CI: 0.01, 0.01) (Fig. 3) (Data set 1). In addition, the pooled prevalence of the three most commonly reported minor complications were: thrombocytopenia $0.03 \%$ (95\% CI: 0.03, 0.03), anemia $0.02 \%$ (95\% CI: 0.02, 0.03), and hepatitis $0.01 \%$ (95\% CI: 0.01, 0.01) (Data set 2). Among 42,325 severity cases, 152 cases resulted in death $(0.36 \%)$.

The prevalence of severe anemia between $P$. vivax and $P$. falciparum

There were 12 articles selected for comparing the prevalence of severe anemia between patients with $P$. vivax and $P$. falciparum. The meta-analysis showed that severe anemia was less frequent in patients with $P$. vivax compared to those with $P$. falciparum $(P$-value $<0.00001$, $\mathrm{OR}=0.38,95 \% \mathrm{CI}=0.25-0.56, \mathrm{I}^{2}=87 \%$ ) (Fig. 5). Considering each included study, none of these studies reported a higher incidence of severe anemia than those with $P$. falciparum. 
Table 1 Clinical characteristic of included studies (49 prevalence studies)

\begin{tabular}{|c|c|c|}
\hline Major complication (WHO, 2014) & Total patients with severity sign & $\begin{array}{l}\text { Severity rate (\%) } \\
\text { Total P.vivax, } 42,325 \text { cases }\end{array}$ \\
\hline Respiratory distress & 566 & 1.34 \\
\hline Acidosis & 44 & 0.10 \\
\hline Pulmonary edema & 126 & 0.30 \\
\hline Death & 152 & 0.36 \\
\hline Cerebral malaria & 471 & 1.11 \\
\hline Convulsion & 75 & 0.18 \\
\hline ARF & 355 & 0.84 \\
\hline Prostration & 26 & 0.06 \\
\hline Hypotension/shock & 267 & 0.63 \\
\hline Jaundice & 634 & 1.50 \\
\hline Severe anemia & 1001 & 2.37 \\
\hline Bleeding/DIC & 242 & 0.57 \\
\hline Hyperparasitemia & 31 & 0.07 \\
\hline Hypoglycemia & 65 & 0.15 \\
\hline \multicolumn{3}{|l|}{ Minor complication } \\
\hline Hyperpyrexia & 57 & 0.13 \\
\hline Severe vomiting & 139 & 0.33 \\
\hline Drowsiness & 123 & 0.29 \\
\hline Hepatitis & 308 & 0.73 \\
\hline Respiratory (NS*) & 1 & 0.00 \\
\hline Severe vomiting & 1 & 0.00 \\
\hline Sudden cardiac arrest & 7 & 0.02 \\
\hline Hemoglobinuria/Hematuria & 143 & 0.34 \\
\hline Anemia & 1008 & 2.38 \\
\hline Thrombocytopenia & 1243 & 2.94 \\
\hline
\end{tabular}

*NS Not specified

\section{The prevalence of thrombocytopenia between $P$. vivax} and $P$. falciparum

There were 6 articles selected for comparing the prevalence of thrombocytpenia between patients with $P$. vivax and $P$. falciparum. The subgroup analysis showed a nonsignificant difference in thrombocytopenia among $P$. vivax and $P$. falciparum $\left(P\right.$-value $\left.=0.23, \mathrm{I}^{2}=87 \%\right)$. Considering each included study, none of these studies reported a difference in thrombocytopenia among $P$. vivax and $P$. falciparum.

\section{Analysis of case reports}

The association between patient characteristics and patient outcomes are shown in Table 3. Patients who developed impaired consciousness had well response (Discharged $\leq 7$ days) when compared to other complications $(P$-value $=0.001,95 \% \mathrm{CI}=0.14(0.04-0.46))$. Patients who developed convulsion had poor response (Discharged $>7$ days) when compared to other complications $(P$-value $<0.0001,95 \% \quad \mathrm{CI}=3.93 \quad(2.15-6.18))$.
Patients who developed respiratory distress had poor response (Discharged $>7$ days) when compared to other complications $\quad(P$-value $=0.009, \quad 95 \% \quad C I=5.47 \quad(1.5-$ 21.39)). Patients who developed renal failure had poor response (Discharged $>7$ days) when compared to other complications $\quad(P$-value $=0.008, \quad 95 \% \quad \mathrm{CI}=7.08 \quad(1.46-$ 34.4)). Patients who developed jaundice had poor response (Discharged $>7$ days) when compared to other complications $\quad(P$-value $=0.021, \quad 95 \% \quad \mathrm{CI}=8.69 \quad(1.05-$ 72.1)). Patients who developed urine (anuria/oliguria) had poor response (Discharged $>7$ days) when compared to other complications $(P$-value $=0.021,95 \% \mathrm{CI}=8.69$ $(1.05-72.1))$. Patients who developed splenomegaly at presentation had well response (Discharged $\leq 7$ days) when compared to other complications $(P$-value $=0.009$, $95 \% \mathrm{CI}=0.23(0.08-0.72))$. Patients who developed complications after the first anti-malarial drugs had poor response (Discharged $>7$ days) when compared to other complications $(P$-value $=0.027,95 \% \mathrm{CI}=3.35(1.12-10)$ ) . The results also showed that patients who developed 


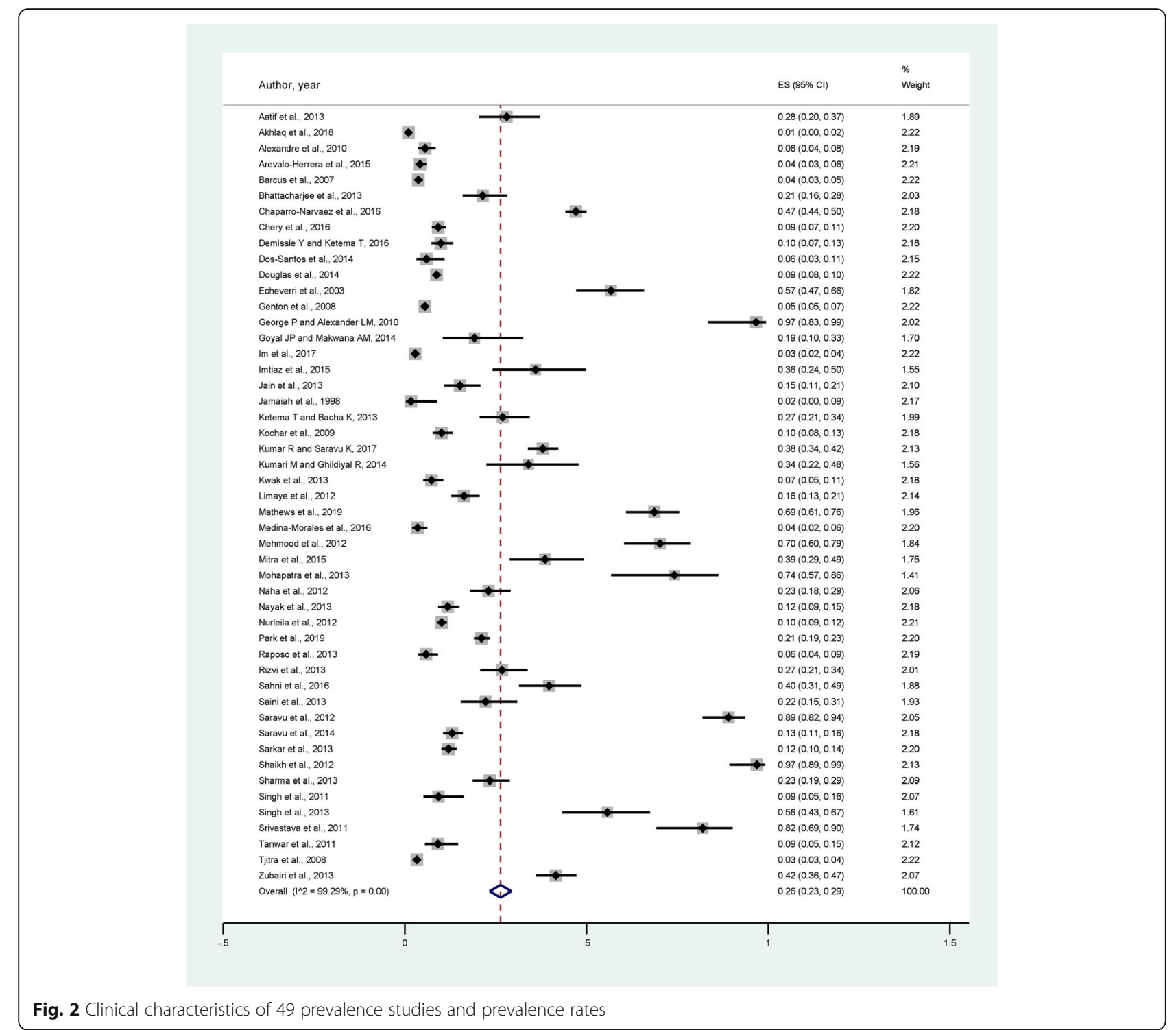

complications after the first drug regimen significantly required a second drug regimen $(P$-value $=0.001,95 \%$ $\mathrm{CI}=9.57$ (1.95-46.98)) (Data set 3).

The association between patient characteristics and time point of severe manifestation is demonstrated in Table 4. The results showed that respiratory distress was associated with the time point of severe manifestation $(P$-value $=0.002)$. Among 22 patients present with respiratory distress, $8(36.4 \%)$ patients developed respiratory distress before treatment, 9 (40.9\%) patients developed respiratory distress after treatment with antimalarial drugs, and 5 (22.7\%) patients developed respiratory distress before and after treatment. Among 28 patients present with renal failure, 22 (78.6\%) patients developed renal failure before treatment, 1 (3.6\%) patient developed renal failure before treatment, and 5 (17.9\%) patients developed renal failure before and after treatment $(P$-value $=0.016)$. Among 8 patients developed bleeding, 2 (25\%) developed bleeding before treatment, 2 (25\%) patients developed bleeding before treatment, and 4 (50\%) patients developed bleeding before and after treatment $(P$-value $=0.016)$. Among 12 patients present with headache, 4 (33.3\%) patients developed complications before treatment, $6(28 \%)$ patients developed complications after treatment, and 2 (16.7\%) patients developed complications before and after treatment $(P$ value $=0.016$ ). Among 7 patients present with rash, 4 (57.1\%) patients developed complications before treatment, no patients developed complications before treatment, and $3(42.9 \%)$ patients developed complications before and after treatment $(P$-value $=0.032)$. Among 19 patients with urine output abnormality, 15 (78.9\%) 
Table 2 Clinical characteristics of 76 patients (from case reports) Clinical Characteristics Frequency (percent)

$$
-\leq 2010
$$

$38(50)$

$$
->2010
$$

Age, mean (SD)

Impaired consciousness

$$
\text { - Yes }
$$$$
\text { - No }
$$

Pulmonary edema

- Yes

- No

Renal failure

- Yes

- No

Severe anemia

$$
\begin{aligned}
& \text { - Yes } \\
& \text { - No }
\end{aligned}
$$

Bleeding

$$
\text { - Yes }
$$$$
\text { - No }
$$

Jaundice

- Yes

- No

Acidosis

- Yes

- No

Hyperparasitemia

- Yes

- No

Respiratory distress

$$
\begin{aligned}
& \text { - Yes } \\
& \text { - No }
\end{aligned}
$$

Convulsion

$$
\begin{aligned}
& \text { - Yes } \\
& \text { - No }
\end{aligned}
$$

Prostration

$$
\text { - Yes }
$$$$
\text { - No }
$$

Gender

$$
\begin{aligned}
& \text { - Male } \\
& \text { - Female }
\end{aligned}
$$

Country of infection

$$
\text { - India }
$$$$
\text { - Non-India }
$$

Days of fever
38 (50)

30.1 (11.5)

21 (27.6)

25 (22.4)

$3(3.9)$

73 (96.1)

$28(36.8)$

$48(63.2)$

8 (10.5)

$68(89.5)$

8 (10.5)

$68(89.5)$

19 (25)

57 (75)

4 (5.3)

$72(94.7)$

2 (2.6)

74 (97.4)

\begin{tabular}{|c|c|}
\hline Clinical Characteristics & Frequency (percent) \\
\hline \multicolumn{2}{|l|}{ Cough } \\
\hline - Yes & $6(7.9)$ \\
\hline$-\mathrm{No}$ & $70(92.1)$ \\
\hline \multicolumn{2}{|l|}{ Weakness } \\
\hline - Yes & $9(11.8)$ \\
\hline$-\mathrm{No}$ & $67(88.2)$ \\
\hline \multicolumn{2}{|l|}{ Headache } \\
\hline - Yes & $12(15.8)$ \\
\hline$-\mathrm{No}$ & $64(84.2)$ \\
\hline \multicolumn{2}{|l|}{ Malaise } \\
\hline - Yes & $3(3.9)$ \\
\hline$-\mathrm{No}$ & $73(96.1)$ \\
\hline \multicolumn{2}{|l|}{ Rash } \\
\hline - Yes & $7(9.2)$ \\
\hline$-\mathrm{No}$ & $69(90.8)$ \\
\hline \multicolumn{2}{|l|}{ Urine output abnormality } \\
\hline - Yes & $19(25)$ \\
\hline$-\mathrm{No}$ & $57(75)$ \\
\hline \multicolumn{2}{|l|}{ Chills } \\
\hline - Yes & $36(47.4)$ \\
\hline$-\mathrm{No}$ & $40(52.6)$ \\
\hline \multicolumn{2}{|l|}{ Rigors } \\
\hline - Yes & $27(35.5)$ \\
\hline$-\mathrm{No}$ & $49(64.5)$ \\
\hline \multicolumn{2}{|l|}{ Abdominal pain } \\
\hline - Yes & 15 (19.7) \\
\hline$-\mathrm{No}$ & $61(80.3)$ \\
\hline \multicolumn{2}{|l|}{ Nausea } \\
\hline - Yes & $6(7.9)$ \\
\hline$-\mathrm{No}$ & $70(92.1)$ \\
\hline \multicolumn{2}{|l|}{ Vomiting } \\
\hline - Yes & $15(19.7)$ \\
\hline$-\mathrm{No}$ & $61(80.3)$ \\
\hline \multicolumn{2}{|l|}{ Edema } \\
\hline - Yes & $1(1.3)$ \\
\hline$-\mathrm{No}$ & 75 (98.7) \\
\hline Temperature, mean (SD) & $38.5(1.04)$ \\
\hline Systolic blood pressure, mean (SD) & $107.6(24.5)$ \\
\hline Diastolic blood pressure, mean (SD) & $69(15.9)$ \\
\hline Pulse rate, mean (SD) & $110.9(19.9)$ \\
\hline Respiratory rate, mean (SD) & $30.3(11.5)$ \\
\hline \multicolumn{2}{|l|}{ Splenomegaly } \\
\hline - Yes & $23(30.3)$ \\
\hline
\end{tabular}

$22(28.9)$

54 (71.1)

8 (10.5)

$68(89.5)$

1 (1.3)

75 (98.7)

48 (64)

27 (36)

59 (77.6)

17 (22.4)

5.71 (2.58)
Table 2 Clinical characteristics of 76 patients (from case reports) (Continued) 
Table 2 Clinical characteristics of 76 patients (from case reports) (Continued)

\begin{tabular}{ll}
\hline Clinical Characteristics & Frequency (percent) \\
\hline - No & $53(69.7)$ \\
Hepatomegaly & $17(22.4)$ \\
- Yes & $59(77.6)$ \\
- No & $9.47(2.79)$ \\
Hemoglobin, mean (SD) & $6237.8(2722.2)$ \\
Leukocyte, mean (SD) & $85,360(74,296.5)$ \\
Platelet, mean (SD) & \\
RDT & $43(56.6)$ \\
- Yes & $33(43.4)$ \\
- No & \\
Time point of severe complications & $50(65.8)$ \\
- Before treatment (at presentation) & $16(21.1)$ \\
- After treatment (with anti-malarial drug) & $10(13.2)$ \\
- Before and after treatment & \\
Complication during treatment & $34(44.7)$ \\
- Yes & $42(55.3)$ \\
- No & \\
Second anti-malarial drug given & $13(17.1)$ \\
- Yes & $63(82.9)$ \\
- No & \\
Discharge/recovery/parasite clearance & $41(65.1)$ \\
- > 7 days & $22(34.9)$ \\
\hline
\end{tabular}

patients developed complications before treatment, no patients developed complications before treatment, and 4 (21.1\%) patients developed complications before and after treatment $(P$-value $=0.027)$.

Differences in patient characteristics and days of response are demonstrated in Table 5. The results showed that patients with poor response had a greater mean days of fever before presentation $($ mean $=6.05)$ than those with well response $($ mean $=4.78, P$-value $=0.04)$. The results also showed that patients with poor response had more mean pulse rate $($ mean $=114.9)$ than those with well response $($ mean $=101.2, P$-value $=0.04)$. Multivariate regression analysis demonstrated no association between patients with poor response and mean pulse rate after the multivariate regression analysis was performed by using age as a covariate $(P$-value $=0.057)$.

\section{Discussion}

This analysis showed a large increase in publication on severe vivax malaria from year 1998-2013 with a maximum number of publications found in year 2013 (14, $28.6 \%)$. The numbers of publication were continuously decreased from year 2014-2018. That fluctuation seems likely due to underreporting or low number of severe vivax cases found in the last century, and only few data to support the dangers of $P$. vivax infections. Plasmodium species remained tagged with the term 'benign' in the last century. However, in recent years which peaked in 2013, a number of studies conducted in India [2937], Sudan [38], Ethiopia [39], Korea [40], Brazil [41], and Pakistan [42] suggested a stronger association between $P$. vivax infections and severe manifestations, so that the number of publications on severe vivax and death were recognized than in previous centuries. The geographic distribution and the incidence of severe manifestations of vivax malaria were very specific and frequently found in some areas of the world. About half of these studies came from India $(25,51 \%)$ and also from other countries including Brazil, Colombia, Ethiopia, Indonesia, Korea, Malaysia, and Pakistan. This is very interesting because no prevalence of severe vivax malaria has been reported in other endemic regions such as Thailand, Cambodia, Lao, Burma, and Vietnam. However, a few case reports of severe vivax malaria have been found in Thailand [18]. In these reports, patients developed pulmonary edema after being treated with anti-malarial drugs.

The highest number of severity cases (629 cases) was found at Rumah Sakit Mitra Masyarakat (RSMM) hospital during 2004-2007 in India [43]. The pooled prevalence of the present study indicated that severe anemia, jaundice, respiratory distress, impaired consciousness, and acute renal failure were the most common complications found among 42,325 severity cases. Our results were in contrast to a previous systematic review indicating that severe thrombocytopenia $\left(<50,000 / \mathrm{mm}^{3}\right)$ was the most common severe manifestation of severe vivax malaria at the beginning of year 2014 [44]. This might be due to the selection of articles in the study, whereas we selected more updated prevalence publications than their study with 19 studies in year 2014-2019. The present study found a large number of severe malarial anemia (hemoglobin $<5 \mathrm{~g} / \mathrm{dl}$ ) among patients with severe vivax malaria (87\%) which was higher than among patients with severe falciparum malaria (73\%) [43]. The severe anemia suggested that the death of infected reticulocytes led to severe anemia by stopping the supply of mature red blood cells $[45,46]$. A previous study indicated that $P$. vivax malaria carries a well-known risk of splenic rupture, considered greater than for falciparum malaria thereby increasing the risk of severe malaria in vivax malarial patients [47]. Our meta-analysis showed that severe anemia occurred less frequently in patients with $P$. vivax compared to those with $P$. falciparum. It is believed that this is due to $P$. falciparum with a higher parasitemia causing a rapid drop in the hemoglobin level 

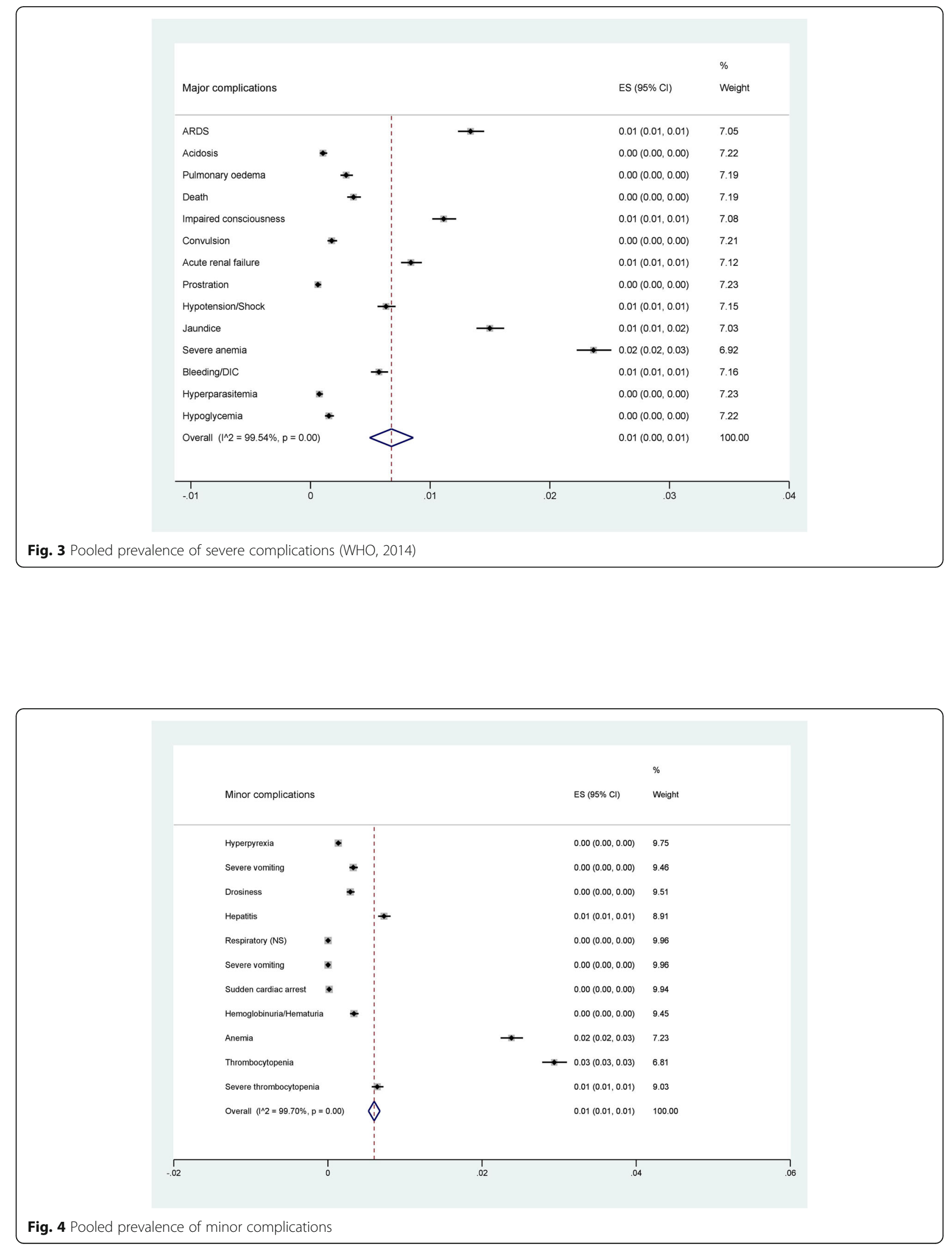


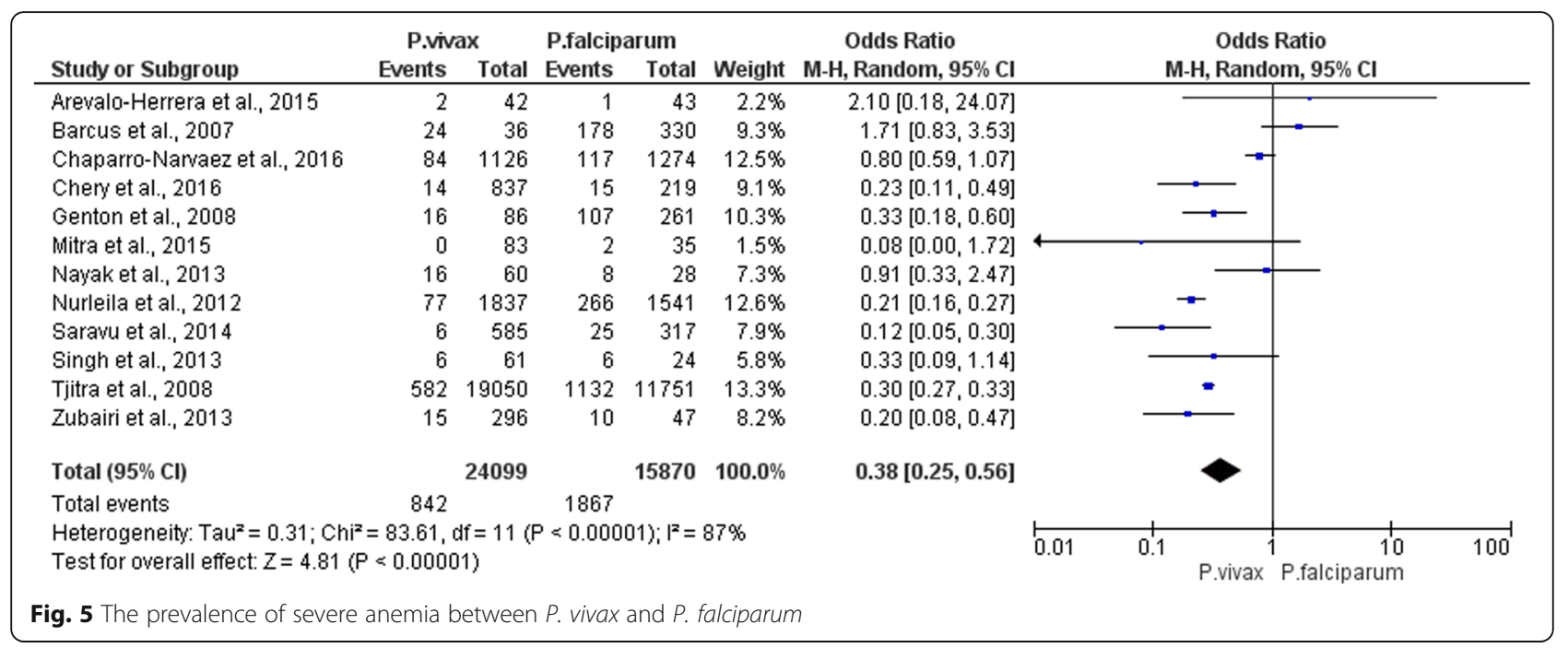

resulting in severe anemia [48]. Moreover, the severe anemia caused by $P$. vivax infection was due to the accumulation of smaller hemoglobin decrements with each recurrent infection [48].

In this study, minor complications of severe malaria which were not based on the WHO criteria were also demonstrated. The results indicated that thrombocytopenia and severe thrombocytopenia was the most common minor complications. Thrombocytopenia in patients with $P$. vivax and $P$. falciparum infection were the most common malaria-associated hematological complications [49]. However, the mechanisms are still unknown. Several mechanisms have been proposed to explain malaria thrombocytopenia. Some studies suggested that thrombocytopenia in malaria might be caused by platelet activation, consumption [50], and platelet apoptosis [28] which leads to destruction by the immune system [51]. Our results were in accordance with a previous systematic review indicating that $10.1 \%$ of patients with $P$. vivax had severe to very severe thrombocytopenia [52]. Moreover, one study indicated that patients with severe $P$. vivax had a 2.8 -fold higher risk of developing severe thrombocytopenia than those with severe P. falciparum malaria [53].

Analysis from the case reports showed that patients who developed impaired consciousness and splenomegaly had well response (Discharged $\leq 7$ days) whereas patients who developed convulsion, respiratory distress, renal failure, urine (anuria/oliguria), jaundice, and complications after being treated with the first anti-malarial drugs had poor response (Discharged $>7$ days). A previous study demonstrated splenomegaly and altered consciousness were more frequent in cases of severe vivax malaria and suggested that these symptoms could indicate a poor prognosis of malaria [54]. For respiratory distress, a previous study indicated that treatment of $P$. vivax resulted in initial worsening of airflow obstruction and gas transfer, which took 6 hours to 8 days after the initiation of anti-malarial treatment [55]. Patients who develop respiratory distress required the mechanical ventilation and other advanced life-support strategies, were delayed in receiving a diagnosis and efficient treatment which can lead to mortality [56]. The results also demonstrated that respiratory distress was associated with the time point of severe manifestations. The present study indicated that 8 patients (36.4\%) developed respiratory distress before treatment and 9 patients (40.9\%) developed respiratory distress after treatment with anti-malarial drugs. In patients with post- respiratory distress, it is suggested that inflammatory reaction occurred within lung microstructure after treatment with anti-malarial drugs was the cause of the in respiratory impairment $[55,57]$. It is also needs to be recognized that convulsion in $P$. vivax infection may lead to poor outcome and increased mortality in $P$. vivax malaria. For renal failure, treatment of malaria-associated kidney diseases required a long-term duration due to management of appropriate antimalarial drugs, hydroelectrolytic disturbance corrections, fluid replacement, and dialysis [58]. A previous study indicated that early initiation of dialysis for acute renal failure was associated with good outcomes by reducing case fatality and increasing renal recovery [59]. In our study, most of the patients developed renal failure before treated with anti-malarial drugs (22, 78.6\%). A previous study indicated that $P$. vivax malaria can cause renal failure more commonly than $P$. falciparum malaria, where renal ischemia was the dominant pathogenic mechanism [60].

According to the WHO criteria, jaundice is one of the cardinal manifestations of severe malaria in adults [2]. This study indicated that patients with jaundice had 
Table 3 Association between patient characteristics and days of well response

\begin{tabular}{|c|c|c|c|c|}
\hline \multirow{2}{*}{$\begin{array}{l}\text { Patient } \\
\text { Characteristics }\end{array}$} & \multicolumn{2}{|c|}{ Days of well response } & \multirow[t]{2}{*}{$\boldsymbol{P}$-value* } & \multirow{2}{*}{$\begin{array}{l}\text { Odd's ratio } \\
(95 \% \mathrm{Cl})\end{array}$} \\
\hline & $\geq 7$ days & $<7$ days & & \\
\hline \multicolumn{5}{|c|}{ Impaired consciousness } \\
\hline - Yes & $7(17.1)$ & $13(59.1)$ & 0.001 & $0.14(0.04-0.46)$ \\
\hline - No & $34(82.9)$ & $9(40.9)$ & & \\
\hline \multicolumn{5}{|l|}{ Convulsion } \\
\hline - Yes & 0 & $8(4.5)$ & $<0.0001$ & $3.93(2.15-6.18)$ \\
\hline - No & $41(100)$ & $14(99.5)$ & & \\
\hline \multicolumn{5}{|l|}{ ARDS } \\
\hline - Yes & $19(46.3)$ & $3(13.6)$ & 0.009 & $5.47(1.5-21.39)$ \\
\hline$-\mathrm{No}$ & $22(53.7)$ & $19(86.4)$ & & \\
\hline \multicolumn{5}{|l|}{ Renal failure } \\
\hline - Yes & $17(41.5)$ & $2(9.1)$ & 0.008 & $7.08(1.46-34.4)$ \\
\hline - No & $24(58.5)$ & $20(90.9)$ & & \\
\hline \multicolumn{5}{|l|}{ Jaundice } \\
\hline - Yes & $12(29.3)$ & $1(4.5)$ & 0.021 & $8.69(1.05-72.1)$ \\
\hline$-\mathrm{No}$ & $29(70.7)$ & $21(95.5)$ & & \\
\hline \multicolumn{5}{|c|}{ Urine (anuria/oliguria) } \\
\hline - Yes & $12(29.3)$ & $1(4.5)$ & 0.021 & $8.69(1.05-72.1)$ \\
\hline - No & $29(70.7)$ & $21(95.5)$ & & \\
\hline \multicolumn{5}{|l|}{ Splenomegaly } \\
\hline - Yes & $9(22)$ & $12(54.5)$ & 0.009 & $0.23(0.08-0.72)$ \\
\hline - No & $32(78)$ & $10(45.5)$ & & \\
\hline \multicolumn{5}{|c|}{ Complications during treatment } \\
\hline - Yes & $25(61)$ & $7(31.8)$ & 0.027 & $3.35(1.12-10)$ \\
\hline \multirow[t]{3}{*}{ - No } & $16(39)$ & $15(68.2)$ & & \\
\hline & Required & & & \\
\hline & Yes & No & & \\
\hline \multicolumn{5}{|c|}{ Complications during treatment } \\
\hline - Yes & $11(84.6)$ & $23(36.5)$ & 0.001 & $9.57(1.95-46.98)$ \\
\hline$-\mathrm{No}$ & $2(15.4)$ & $40(63.5)$ & & \\
\hline
\end{tabular}

*Pearson Chi-Square

poor response to treatment (Discharged $>7$ days). Jaundice in malaria is caused by destruction of parasitized RBCs leading to massive intravascular hemolysis, resulting in hepatic dysfunction and severe anemia [61, 62]. A previous study indicated that treatment of $P$. vivax with IV artesunate rapidly reduced parasitemia levels; however, patients underwent post-treatment hemolysis with the higher doses of IV artesunate [63]. This post-treatment hemolysis may induce jaundice, hemoglobinuria, hepatomegaly, or severe malaria after treatment with the first anti-malarial drugs. However, no higher doses of IV artesunate had been reported among 76 cases.
This study also showed that patients with poor response had more mean days of fever before presentation $($ mean $=6.05)$ than those with well response (mean = 4.78, $P$-value $=0.04$ ). Fever in malaria is believed to be associated with release of toxins and antigenic substances, which induce the release of cytokines by white blood cells. Our study results indicated poor prognosis of patients who had more days of fever before presentation. During treatment, fever in severe malaria usually resolves by Day 4 to 5 and needs prompt investigations in case of a prolonged fever after severe malaria [64]. To our knowledge, the prolonged fever before presentation was caused by the human body tries to clear parasites 
Table 4 Association between patient characteristics and time of severe manifestation

\begin{tabular}{|c|c|c|c|c|}
\hline \multirow{2}{*}{$\begin{array}{l}\text { Patient } \\
\text { Characteristics }\end{array}$} & \multicolumn{3}{|c|}{ Time of severe manifestation } & \multirow{2}{*}{$\begin{array}{l}\boldsymbol{P} \text { - } \\
\text { value* }\end{array}$} \\
\hline & Before treatment & After treatment & Before and after treatment & \\
\hline \multicolumn{5}{|l|}{ ARDS } \\
\hline - Yes & $8(36.4)$ & $9(40.9)$ & $5(22.7)$ & \multirow[t]{2}{*}{0.002} \\
\hline$-\mathrm{No}$ & $42(77.8)$ & $7(13)$ & $5(9.3)$ & \\
\hline \multicolumn{5}{|l|}{ Renal failure } \\
\hline - Yes & $22(78.6)$ & $1(3.6)$ & $5(17.9)$ & \multirow[t]{2}{*}{0.016} \\
\hline$-\mathrm{No}$ & $28(58.3)$ & $15(31.2)$ & $5(10.4)$ & \\
\hline \multicolumn{5}{|l|}{ Bleeding } \\
\hline - Yes & $2(25)$ & $2(25)$ & $4(50)$ & \multirow[t]{2}{*}{0.003} \\
\hline - No & $48(70.6)$ & $14(20.6)$ & $6(8.8)$ & \\
\hline \multicolumn{5}{|l|}{ Headache } \\
\hline - Yes & $4(33.3)$ & $6(50)$ & $2(16.7)$ & \multirow[t]{2}{*}{0.018} \\
\hline - No & $46(71.9)$ & $10(15.6)$ & $8(12.5)$ & \\
\hline \multicolumn{5}{|l|}{ Rash } \\
\hline - Yes & $4(57.1)$ & 0 & $3(42.9)$ & \multirow[t]{2}{*}{0.032} \\
\hline - No & $46(66.7)$ & $16(23.2)$ & $10(10.1)$ & \\
\hline \multicolumn{5}{|c|}{ Urine (anuria/oliguria) } \\
\hline - Yes & $15(78.9)$ & 0 & $4(21.1)$ & \multirow[t]{2}{*}{0.027} \\
\hline - No & $35(61.4)$ & $16(28.1)$ & $6(10.5)$ & \\
\hline
\end{tabular}

*Pearson Chi-Square

for a period of time until patients present at the hospital. Although the significant difference between days of fever and poor response existed, this information should be carefully interpreted and needs to be confirmed by further studies with a greater sample size to gain significant data on daily practice.

The results of the present study also showed that patients with poor response had a greater mean pulse rate than those with well response. We thought it could be cardiovascular involvement related to the previous studies, indicating that $P$. vivax infection is associated with rare and serious cardiovascular complications [65]. Although the results of greater mean pulse rate were related to poor outcome of patients, there were other variables such as fever that could be confounding factors. From the present data, the multivariate analysis of fever as a covariate could not be performed because most

Table 5 Differences in patient characteristics and days of response

\begin{tabular}{|c|c|c|c|}
\hline \multirow[t]{2}{*}{ Parameters } & \multicolumn{2}{|c|}{ Days of response, mean $\pm \mathrm{SD}(\mathrm{N})$} & \multirow{2}{*}{$\begin{array}{l}P \text { - } \\
\text { value* }\end{array}$} \\
\hline & $\geq 7$ days & $<7$ days & \\
\hline Age & $29.4 \pm 11.5(41)$ & $27.1 \pm 16.7(21)$ & 0.6 \\
\hline Days of fever & $6.05 \pm 2.58(37)$ & $4.78 \pm 2.89(22)$ & 0.04 \\
\hline Pulse (per minute) & $114.9 \pm 20(32)$ & $101.2 \pm 18.9(13)$ & 0.04 \\
\hline Temperature $\left({ }^{\circ} \mathrm{C}\right)$ & $38.5 \pm 1.08(26)$ & $38.4 \pm 1.04(8)$ & 0.76 \\
\hline Respiratory rate (per minute) & $33.1 \pm 12.6(18)$ & $26 \pm 8.74(10)$ & 0.08 \\
\hline Systolic blood pressure $(\mathrm{mmHg})$ & $102.8 \pm 21.2(35)$ & $103.2 \pm 22.9(15)$ & 0.69 \\
\hline Diastolic blood pressure $(\mathrm{mmHg})$ & $65.4 \pm 12.3(34)$ & $67.8 \pm 16(15)$ & 0.28 \\
\hline Hemoglobin (g/dL) & $10.1 \pm 2.79$ & $9.78 \pm 2.67$ & 0.69 \\
\hline Leukocyte count $\left(\times 10^{3}\right.$ cell/ $\left.\mu \mathrm{L}\right)$ & $6421.6 \pm 2767.4(19)$ & $5900 \pm 2943.9(10)$ & 0.61 \\
\hline Platelet count $\left(\times 10^{3}\right.$ cell/ $\left.\mu \mathrm{L}\right)$ & $92,300 \pm 85,080(10)$ & $50,700 \pm 38,496(3)$ & 0.45 \\
\hline
\end{tabular}


patients in the case reports were presented with fever at presentation $(74 / 76,97.4 \%)$. This analysis needs to be confirmed by further studies.

\section{Limitations}

The present study had a main limitation in that we could not retrieve all full-text and non-English articles that passed our inclusion criteria.

\section{Conclusion}

Severe anemia was the most common major manifestation of $P$. vivax malaria. Severe anemia was found less frequently in patients with $P$. vivax than those with $P$. falciparum. Renal failure, jaundice, anuria/oliguria, and complication during treatment along with mean days of fever and higher pulse rates at presentation might be predictors of poor outcome of patients with severe vivax malaria.

\section{Supplementary information}

Supplementary information accompanies this paper at https://doi.org/10. 1186/s12879-020-05046-y.

Additional file 1. Data set 1.

Additional file 2. Data set 2.

Additional file $\mathbf{3}$. Data set 3.

\section{Abbreviations}

ISI: Web of Science; WHO: World Health Organization

\section{Acknowledgements}

The authors would like to thank all published research that contributed to the data used in this study.

\section{Authors' contributions}

MK carried out the study design, study selection, data extraction, statistical analysis, and drafted the manuscript. KUK participated in the study selection, data extraction, and drafted the manuscript. GDM and FRM participated in the study selection, and writing of the paper. All authors read and approved the final manuscript.

\section{Funding}

This research was partially supported by the new strategic research (P2P) project, Walailak University, Thailand. The funders had a role in the collection, analysis, and interpretation of the data.

\section{Availability of data and materials}

All data generated or analyzed during this study are included in this manuscript and its supplementary information files.

\section{Ethics approval and consent to participate}

Not applicable.

\section{Consent for publication}

Not applicable.

\section{Competing interests}

The authors declare that there is no conflict of interest regarding the publication of this article.

\section{Author details}

TMedical Technology, School of Allied Health Sciences, Walailak University, Thasala, Nakhon Si Thammarat, Thailand. ${ }^{2}$ Department of Medical

Technology, Far Eastern University, Manila, Philippines.

Received: 31 January 2020 Accepted: 20 April 2020

Published online: 24 May 2020

\section{References}

1. World Health Organization. World malaria report. Geneva: World Health Organization; 2019.

2. World Health Organization. Guidelines for the treatment of malaria. Geneva: World Health Organization; 2015.

3. Kute VB, Vanikar AV, Ghuge PP, Goswami JG, Patel MP, Patel HV, et al. Renal cortical necrosis and acute kidney injury associated with Plasmodium vivax: a neglected human malaria parasite. Parasitol Res. 2012;111(5):2213-6.

4. Mehndiratta S, Rajeshwari K, Dubey AP. Multiple-organ dysfunction in a case of Plasmodium vivax malaria. J Vector Borne Dis. 2013:50(1):71-3.

5. Kute VB, Goswami JG, Vanikar AV, Shah PR, Gumber MR, Patel HV, et al. Unusual presentation of Plasmodium vivax: a neglected human malaria parasite. Parasitol Res. 2012;110(6):2573-6.

6. Raj MA, Hariprasad S, Rohini K, Acharya V, Krishna SBA. Spontaneous subdural haemorrhage: a rare association with plasmodium vivax malaria. J Clin Diagn Res. 2016:10(1):OD05-OD6.

7. Karanth SS, Marupudi KC, Gupta A. Intracerebral bleed, right haemiparesis and seizures: an atypical presentation of vivax malaria. BMJ Case Rep. 2014; 2014:bcr2014204833.

8. Arora S, Aggarwal A, Kanwar SS, Nayyar PS. Purpura fulminans in Plasmodium vivax malaria. J Indian Acad Clin Med. 2018;19(3):230-2.

9. Valecha N, Pinto RGW, Turner GDH, Kumar A, Rodrigues S, Dubhashi NG, et al. Case report: histopathology of fatal respiratory distress caused by Plasmodium vivax malaria. Am J Trop Med Hyg. 2009;81(5):758-62.

10. Anvikar AR, Singh DK, Singh R, Dash AP, Valecha N. Vivax malaria presenting with cerebral malaria and convulsions. Acta Parasitol. 2010;55(1):96-8.

11. Khan YA, Mian UH, Ghanchi NK, Zubairi ABS, Beg MA. Neurological involvement associated with Plasmodium vivax malaria from Pakistan. Trop Dr. 2018:48(1):52-4.

12. Pothapregada S, Kamalakannan B. Hemophagocytic syndrome in Plasmodium vivax malaria. J Vector Borne Dis. 2014:51(2):144-6.

13. Joon YS, Cheong WP, You MJ, Jeong YK, Jeong HK, Hyo JY, et al. Two cases of Plasmodium vivax malaria with the clinical picture resembling toxic shock. Am J Trop Med Hyg. 2007;77(4):609-11.

14. Fitri LE, Sardjono TW, Hermansyah B, Candradikusuma D, Berens-Riha N. Unusual presentation of vivax malaria with anaemia, thrombocytopenia, jaundice, renal disturbance, and melena: a report from Malang, a nonendemic area in Indonesia Case Rep Infect Dis. 2013:2013.686348.

15. Sinha S, Mukherji A, Chandrakar S. Hypokalaemic paralysis in an adult case of Plasmodium vivax malaria. Malaria J. 2013;12(1):111.

16. Aashish A, Manigandan G. Complicated vivax malaria, an often underestimated condition - case report. J Fam Community Med. 2015. 22(3):180-2.

17. Illamperuma C, Allen BL. Pulmonary edema due to Plasmodium vivax malaria in an American missionary. Infection. 2007:35(5):374-6.

18. Pukrittayakamee $S$, Chantra A, Vanijanonta S, White NJ. Pulmonary oedema in vivax malaria. Trans R Soc Trop Med Hyg. 1998:92(4):421-2.

19. Carlini ME, White AC Jr, Atmar RL. Vivax malaria complicated by adult respiratory distress syndrome. Clin Infect Dis. 1999:28(5):1182-3.

20. Lomar AV, Vidal JE, Lomar FP, Barbas CV, De Matos GJ, Boulos M. Acute respiratory distress syndrome due to vivax malaria: case report and literature review. Braz J Infect Dis. 2005;9(5):425-30

21. Atam $V$, Singh AS, Yathish BE, Das L. Acute pancreatitis and acute respiratory distress syndrome complicating Plasmodium vivax malaria. J Vector Borne Dis. 2013;50(2):151-4

22. Lee HJ, Baek JH, Chae MH, Joo H, Lee JS, Chung MH, et al. A case of vivax malaria complicated by adult respiratory distress syndrome and successful management with extracorporeal membrane oxygenation. Korean J Parasitol. 2013;51(5):551-5.

23. Nasir N, Lalani S, Samani ZA, Almas A. Myocarditis complicating Plasmodium vivax malaria. J Coll Physicians Surg Pak. 2014;24:S96-S8.

24. Sharma V, Sharma A, Aggarwal A, Bhardwaj G, Aggarwal S. Acute pancreatitis in a patient with vivax malaria. JOP. 2012;13(2):215-6. 
25. Liberati A, Altman DG, Tetzlaff J, Mulrow C, Gotzsche PC, loannidis JP, et al The PRISMA statement for reporting systematic reviews and meta-analyses of studies that evaluate healthcare interventions: explanation and elaboration. BMJ. 2009;339:b2700.

26. Nyaga VN, Arbyn M, Aerts M. Metaprop: a Stata command to perform metaanalysis of binomial data. Arch Public Health. 2014;72(1):39.

27. Cochrane community. RevMan 5. 2019 Available from: https:/community. cochrane.org/.

28. Piguet PF, Kan CD, Vesin C. Thrombocytopenia in an animal model of malaria is associated with an increased caspase-mediated death of thrombocytes. Apoptosis. 2002;7(2):91-8.

29. Aatif S, Jamal Q, Altaf A. Is vivax malaria really benign? - a Karachi-based study. J Pak Med Assoc. 2013;63(6):721-4.

30. Bhattacharjee P, Dubey S, Gupta VK, Agarwal P, Mahato MP. The clinicopathologic manifestations of plasmodium vivax malaria in children: a growing menace. J Clin Diagn Res. 2013;7(5):861-7.

31. Jain V, Agrawal A, Singh N. Malaria in a tertiary health care facility of Central India with special reference to severe vivax: implications for malaria control. Pathogens and Global Health. 2013;107(6):299-304.

32. Mohapatra S, Samantaray JC, Arulselvi S, Ghosh A. Disseminated intravascular coagulation following malaria due to Plasmodium vivax: a thromboelastography-based study. Malar J. 2013;12:336.

33. Nayak KC, Meena SL, Gupta BK, Kumar S, Pareek V. Cardiovascular involvement in severe vivax and falciparum malaria. J Vector Borne Dis. 2013;50(4):285-91.

34. Rizvi I, Tripathi D, Chughtai A, Beg M, Zaman S, Zaidi N. Complications associated with Plasmodium vivax malaria: a retrospective study from a tertiary care hospital based in western Uttar Pradesh, India. Ann Afr Med 2013;12(3):155-9.

35. Saini T, Kumhar M, Barjartya HC. Plasmodium vivax malaria--is it really benign? J Indian Med Assoc. 2013;111(9):609-11.

36. Sarkar D, Ray S, Saha M, Chakraborty A, Talukdar A. Clinico-laboratory profile of severe Plasmodium vivax malaria in a tertiary care Centre in Kolkata. Trop Parasitol. 2013;3(1):53-7.

37. Singh R, Kumar S, Rana SK, Thakur B, Singh SP. A comparative study of clinical profiles of vivax and falciparum malaria in children at a tertiary care Centre in Uttarakhand. J Clin Diagn Res. 2013;7(10):2234-7.

38. Abdallah TM, Abdeen MT, Ahmed IS, Hamdan HZ, Magzoub M, Adam I. Severe Plasmodium falciparum and Plasmodium vivax malaria among adults at Kassala Hospital, eastern Sudan. Malaria J. 2013;12(1):148.

39. Ketema T, Bacha K. Plasmodium vivax associated severe malaria complications among children in some malaria endemic areas of Ethiopia. BMC Public Health. 2013;13(1):637

40. Kwak YG, Lee HK, Kim M, Um TH, Cho CR. Clinical characteristics of vivax malaria and analysis of recurred patients. Infect Chemother. 2013; 45(1):69-75

41. Raposo CC, Santos JB, Santos GM, Goncalves Eda G, Silva AR. Plasmodium vivax malaria: related factors to severity in the state of Maranhao, Brazil. Rev Soc Bras Med Trop. 2013:46(1):67-72.

42. Zubairi AB, Nizami S, Raza A, Mehraj V, Rasheed AF, Ghanchi NK, et al. Severe Plasmodium vivax malaria in Pakistan. Emerg Infect Dis. 2013;19(11): $1851-4$.

43. Tjitra $E$, Anstey NM, Sugiarto $P$, Warikar $N$, Kenangalem $E$, Karyana $M$, et al. Multidrug-resistant Plasmodium vivax associated with severe and fatal malaria: a prospective study in Papua, Indonesia. PLoS Med. 2008; 5(6):0890-9.

44. Rahimi BA, Thakkinstian A, White NJ, Sirivichayakul C, Dondorp AM, Chokejindachai W. Severe vivax malaria: a systematic review and metaanalysis of clinical studies since 1900. Malar J. 2014;13:481.

45. McQueen PG, McKenzie FE. Age-structured red blood cell susceptibility and the dynamics of malaria infections. Proc Natl Acad Sci U S A. 2004;101(24):9161-6.

46. Antia R, Yates A, de Roode JC. The dynamics of acute malaria infections. I. Effect of the parasite's red blood cell preference. Proc Biol Sci. 2008; 275(1641):1449-58

47. Buffet PA, Safeukui I, Milon G, Mercereau-Puijalon O, David PH. Retention of erythrocytes in the spleen: a double-edged process in human malaria. Curr Opin Hematol. 2009;16(3):157-64

48. Douglas NM, Lampah DA, Kenangalem E, Simpson JA, Poespoprodjo JR, Sugiarto $P$, et al. Major burden of severe anemia from non-falciparum malaria species in Southern Papua: a hospital-based surveillance study. PLoS Med. 2013;10(12):e1001575 discussion e.
49. Wickramasinghe SN, Abdalla SH. Blood and bone marrow changes in malaria. Best Pract Res Clin Haematol. 2000;13(2):277-99.

50. Lee SH, Looareesuwan S, Chan J, Wilairatana P, Vanijanonta S, Chong SM, et al. Plasma macrophage colony-stimulating factor and P-selectin levels in malaria-associated thrombocytopenia. Thromb Haemost. 1997;77(2):289-93.

51. Erhart LM, Yingyuen K, Chuanak N, Buathong N, Laoboonchai A, Miller RS, et al. Hematologic and clinical indices of malaria in a semi-immune population of western Thailand. Am J Trop Med Hyg. 2004;70(1):8-14.

52. Naing C, Whittaker MA. Severe thrombocytopaenia in patients with vivax malaria compared to falciparum malaria: a systematic review and metaanalysis. Infect Dis Poverty. 2018;7(1):10.

53. Tanwar GS, Khatri PC, Chahar CK, Sengar GS, Kochar A, Tanwar G, et al. Thrombocytopenia in childhood malaria with special reference to P. vivax monoinfection: a study from Bikaner (northwestern India). Platelets. 2012; 23(3):211-6.

54. Mathews SE, Bhagwati MM, Agnihotri V. Clinical spectrum of Plasmodium vivax infection, from benign to severe malaria: a tertiary care prospective study in adults from Delhi, India. Trop Parasitol. 2019;9(2):88-92.

55. Anstey NM, Jacups SP, Cain T, Pearson T, Ziesing PJ, Fisher DA, et al. Pulmonary manifestations of uncomplicated falciparum and vivax malaria: cough, small airways obstruction, impaired gas transfer, and increased pulmonary phagocytic activity. J Infect Dis. 2002;185(9):1326-34.

56. Marks M, Gupta-Wright A, Doherty JF, Singer M, Walker D. Managing malaria in the intensive care unit. Br J Anaesth. 2014;113(6):910-21.

57. Anstey NM, Handojo T, Pain MC, Kenangalem E, Tjitra E, Price RN, et al. Lung injury in vivax malaria: pathophysiological evidence for pulmonary vascular sequestration and posttreatment alveolar-capillary inflammation. J Infect Dis. 2007;195(4):589-96.

58. Kute VB, Shah PR, Munjappa BC, Gumber MR, Patel HV, Jain SH, et al. Outcome and prognostic factors of malaria-associated acute kidney injury requiring hemodialysis: a single center experience. Indian J Nephrol. 2012 22(1):33-8.

59. Wang C, Lv LS, Huang H, Guan J, Ye Z, Li S, et al. Initiation time of renal replacement therapy on patients with acute kidney injury: a systematic review and meta-analysis of 8179 participants. Nephrology (Carlton). 2017; 22(1):7-18.

60. Prakash J, Singh AK, Kumar NS, Saxena RK. Acute renal failure in Plasmodium vivax malaria. J Assoc Physicians India. 2003:51:265-7.

61. Kochar DK, Sirohi P, Abhishek K. Review. Gastroenterol Hepatol. 2006;2(1): 36-8

62. Tatura SNN, Wowor EC, Mandei JM, Wilar R, Warouw SM, Rompis J, et al. Case report: severe Plasmodium vivax malaria mimicking Sepsis in a neonate. Am J Trop Med Hyg. 2018;98(3):656-9.

63. Zoller T, Junghanss T, Kapaun A, Gjorup I, Richter J, Hugo-Persson M, et al. Intravenous artesunate for severe malaria in travelers, Europe. Emerg Infect Dis. 2011:17(5):771-7.

64. Tran TH, Day NP, Nguyen HP, Nguyen TH, Tran TH, Pham PL, et al. A controlled trial of artemether or quinine in Vietnamese adults with severe falciparum malaria. N Engl J Med. 1996;335(2):76-83.

65. Ray HN, Doshi D, Rajan A, Singh AK, Singh SB, Das MK. Cardiovascular involvement in severe malaria: a prospective study in Ranchi, Jharkhand. J Vector Borne Dis. 2017;54(2):177-82

\section{Publisher's Note}

Springer Nature remains neutral with regard to jurisdictional claims in published maps and institutional affiliations.

Ready to submit your research? Choose BMC and benefit from

- fast, convenient online submission

- thorough peer review by experienced researchers in your field

- rapid publication on acceptance

- support for research data, including large and complex data types

- gold Open Access which fosters wider collaboration and increased citations

- maximum visibility for your research: over $100 \mathrm{M}$ website views per year

At BMC, research is always in progress.

Learn more biomedcentral.com/submissions 